\title{
A mammoth murder mystery
}

\author{
Twilight of the Mammoths: Ice Age \\ Extinctions and the Rewilding of America \\ by Paul S. Martin \\ University of California Press: 2005. 269 pp. \\ $\$ 29.95, \notin 18.95$
}

\section{Alan B. Shabel}

In 1877, Richard Owen suggested that the great Pleistocene fossil mammals of Australia had been driven to extinction by ${ }^{\alpha}$ the hostile agency of man". Seven years later, C. S. Wilkinson replied that a reduction in rainfall, leading to the impoverishment of a once rich flora, was a more likely trigger for the loss of these beasts. And so it has always been in the study of late Quaternary extinctions: arguments for anthropogenic causes are countered by arguments in favour of climate change.

It is widely accepted that in the past 50,000 years, the world has lost a diverse array of reptiles, birds and mammals. A striking feature of this mass extinction event is that it disproportionately affected large-bodied vertebrates (more than $45 \mathrm{~kg}$ ). With few exceptions, small vertebrates, plants and insects did not suffer dramaticlosses. Another striking feature is the extinction event's geographic asynchrony: the extinctions occurred first in Australia (about 46,000 years ago) and much later in the Americas $(13,000$ years ago $)$, the West Indies $(5,000$ years ago), Madagascar (2,300 years ago) and New Zealand (500 years ago). On each land mass, the extinctions occurred soon after the immigration of Homo sapiens, and the timing of the extinctions does not correlate with anomalous changes in climate.

In the 1960 s, Paul Martin sparked the modern study of the late Quaternary extinctions with his 'overkill' hypothesis, which argues forcefully for the role of human hunting in the extinction event. In his new book, Twilight of the Mammoths, Martin synthesizes fifty years of his research on the subject in a palaeontological memoir. He takes an extreme position, in two respects. First, he argues that humans

\section{ELECTRIFYING BOOK WINS AVENTIS PRIZE}

David Bodanis has wonthis year's Aventis Prize for science books. His book, Electric Universe: How Electricity Switched on the Modern World published by Little, Brown, was described by the judges as "a very good read" that "opens up a universe of facts that would scarcely be credible in an imaginary tale".

The junior prize went to Kate Petty, Jennie Maizels and Corina Fletcher for their book The Global Garden, inspired by the Eden Project and published by Eden Books (Transworld).

The winners received their awards at a ceremony on 16 May 2006 at the Royal Society in London.

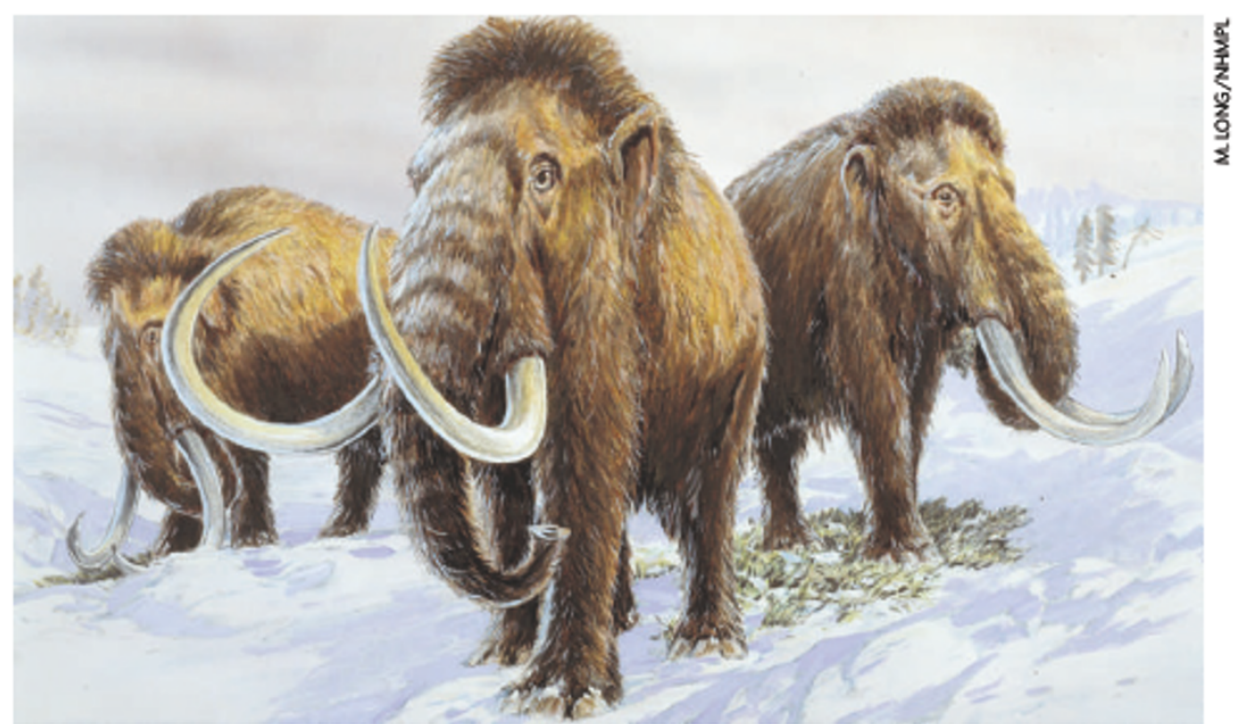

Was climate change or hunting by humans to blame for the demise of large mammals in the Pleistocene?

wiped out the large vertebrates through direct predation pressure; although he acknowledges the potential role of less direct human influences, such as pathogen propagation and artificial fires, he focuses primarily on hunting. Second, he posits that the extinctions occurred extremely quickly; for example, he thinks the whole of North America could have lost its megafauna in "a few tens or hundreds of years".

It is convenient that Martin takes such an extreme position because it renders his model testable. If it can be shown that humans coexisted with megafauna for a thousand years or more, his blitzkrieg version of the overkill model would be in trouble. In most cases, such as in Australia and South America, the palaeontological record is not known in sufficient detail to determine the precise dates of human arrival and megafaunal extinction. But the situation is better in North America and on the large oceanic islands, where the timing of the two phenomena correlate very closely. However, if humans were responsible for such large-scale devastation, where are the archaeological kill sites? In North America, only a dozen or so late Quaternary sites have been found with clear evidence of butchery (and almost all of these are mammoth), and there are no known sites with artistic depictions of humans interacting with any members of the extinct megafauna.

To most observers, the paucity of kill sites constitutes strong evidence against the overkill model. Martin, however, argues that this absence of evidence actually supports his position: if the extinction event was extremely rapid, the devastation would fail to register in the archaeological record. Overkill seems to have become an idée fixe for Martin, and his logic becomes circular at times. For example, he writes: "I have grave doubts about the existence of a widespread and biologically effective human population in the Americas before 13,000 years ago precisely because large, slowmoving, eminently huntable animals such as ground sloths continued to occupy their favorite dung caves in North and South America as late as they did" In other words, he takes the presence of megafauna to signal the absence of humans, because the two could not possibly have coexisted. Martin is certainly more effective when he is working to test his model than when he is assuming it.

As if his overkill hypothesis were not controversial enough, Martin finishes the book with a call to restore lost megafauna through the introduction of closely related species, or ecological proxies, into the 'blighted' areas. In North America, he declares, we ought to restore not only bison and brown bears, but also proboscideans, camels and lions. If giant ground sloths are not available, we could use rhinos as surrogates. Martin recognizes that his solution is not perfect (and that in some cases the political hurdles may be insurmountable), but he argues that this attempt at restoration is "infinitely better than continual attrition".

Whatever scientists may think of Martin's call for 'resurrection ecology', it must be agreed that his perspective fundamentally challenges our conception of what is 'natural'. Many ecologists seek to study systems without a contemporary human presence so they can better assess the pure dynamics of nature. Martin's work impresses on us the fact that Earth's terrestrial ecosystems were profoundly restructured long before European colonialism and industrialization. That, at least, no longer seems controversial.

Alan B. Shabel is in the Depar tment of Integrative Biology, University of California, Berkeley, Berkeley, California 94720-3140, USA. 